\title{
The Regional Kendall test for trend
}

\author{
Dennis R. Helsel* and Lonna M. Frans
}

*U.S. Geological Survey, PO Box 25046, MS 964, Lakewood, CO 80225

Phone: 303.236.5340Ｆax: 303.236.1425 email: dhelsel@usgs.gov

Summary of text

The Regional Kendall test for trend determines whether a consistent trend occurs across many locations within a region. 


\section{Supporting Information Available}

The original Seasonal Kendall program written by J.R. Slack (Hirsch et al., 1984) has been recompiled to run in the DOS window of a modern PC under the Windows operating system. Adaptations to the code were made to run both the Mann-Kendall and Regional Kendall tests for trend. This program is freely available online from the US Geological Survey as part of Scientific Investigations Report 2005-5275 (37), at http://pubs.er .usgs.gov/pubs/sir/sir20055275 .

A freely-available implementation of the Seasonal Kendall test is contained within the U.S. Geological Survey’s “Library for S-Plus” as the program S-ESTREND (EStimate TREND). This library requires that the user must have installed version 6.1 or later of the commercial statistics package S-Plus for Windows ${ }^{\circledR}$ (Insightful Corporation) ${ }^{*}$ on the users computer. The "Library for S-Plus” can be downloaded from the U.S. Geological Survey at:

http://water.usgs.gov/software/statistics.html

Instructions for installing the library are available at the link above.

Other implementations of the Seasonal Kendall test have been published (8) or are available as free or commercial software over the internet. Test data sets with their resulting program outputs are available as part of USGS SIR 2005-5275, and can be used to verify the accuracy of results for other implementations of the Seasonal Kendall test. By substituting "location” for "season” when designating input values, programs for the Seasonal Kendall test should be capable of also computing the Regional Kendall test for trend.

* Use of names of commercial software in this report does not constitute endorsement by the U.S. Geological Survey. 